\title{
The Effect of Fruit-syrup Supplements on the Assimilation of Food from the Alimentary Canal
}

\author{
2. Their Effect on the Growth Rate, Nitrogen Assimilation and Calorie \\ Intake of Young Rats
}

\author{
By H. T. FAWNS AND G. H. BOURNE \\ Departments of Biochemistry and Histology, London Hospital Medical College, \\ Turner Street, London, E. I
}

(Received I4 December 195I)

Several groups of workers have reported that daily supplements of orange or lemon juice exert a favourable effect on the growth rate of children. Thus Chaney (1923) produced a weight increase in 256 undernourished Californian children by a daily ration of oranges with their mid-morning meal. Newall \& Miller (1923) gave $45 \mathrm{ml}$. orange juice daily to fourteen underweight children for 3 months and reported a large increase in their expected gain in weight. Chaney \& Blunt (1925) carried out an extensive investigation on two growing girls (aged 10 and $\mathrm{I}$ I years) receiving a daily addition to their diet of $600-700 \mathrm{ml}$. orange juice. A marked weight increase and an increase in the retention of calcium, phosphorus, magnesium and nitrogen were observed. Less ammonia was excreted in the urine, while the $\mathrm{pH}$ and organic-acid excretion increased. These and other experiments were carried out with the juices of fresh citrus fruits. Information relating to the effects of syrups made from homeproduced fruits such as black currant, strawberry or raspberry, which are widely used in this country, does not appear to be available. These syrups are frequently admixed with milk (e.g. in 'milk shakes') to which they are added as flavouring material.

Though the benefit of a daily milk supplement to growing children is beyond question and is supported by numerous animal experiments, the addition of syrup to milk may influence its nutritional value considerably, as well as that of the basal diet taken at the same time. The results may be either beneficial or detrimental. For instance the additional ascorbic acid and the alkaline nature of the ash from fruit juices should exert a favourable effect, as should also the more rapid disintegration of the milk clot in the stomach, already reported (Fawns \& Bourne, 1953). On the other hand, the presence of $50 \%$ sucrose in the syrups might have a detrimental effect. Firstly, the fermentation of the sucrose by the bacterial flora of the gut might alter the $\mathrm{pH}$ of the intestinal contents in a manner unfavourable to the assimilation of essential constituents. Secondly, the sucrose might supply such a large amount of the subject's caloric needs that the consumption of other foodstuffs, dietetically more beneficial, would be proportionately curtailed with detrimental results to the total nutritional picture. On the other hand, the fruit-juice component of the syrups might act as a stimulant to appetite and result in an increased intake of other constituents. Thirdly, their effect (if any) on the speed of evacuation of the bowel and character of the faeces is uncertain. 
The net result of these various factors, and probably others as well, is difficult to forecast, and the following experiment was therefore carried out on groups of young, growing rats.

\section{EXPERIMENTAL}

Plan of experiment. Where the daily supply of basal ration is suboptimal or its composition inadequate, the beneficial effect of any milk supplement, with or without addition of fruit syrup, would be so marked that any possible detrimental effects resulting from the admixture of syrups would probably be masked. The animals were therefore kept on a nutritionally adequate basal diet and water, both supplied ad lib., and the supplements were superimposed on this. Such a system should have the further advantage of simulating more closely conditions in human nutrition, since mixtures of milk and fruit syrups (usually in the form of 'milk shakes') are most frequently consumed as an extra.

Thirty-six young male rats from the same stock colony were divided into six equal groups. The first 20 days were taken as an initial control period. During this period all six groups received basal ration and water only. During the next 25 days, the first three groups received daily mixtures of milk and loganberry, raspberry or strawberry syrups, while the second three acted as controls, one group receiving milk and $50 \%$ $(w / v)$ sucrose solution, another milk and an equal volume of water and the last one water only. 'The syrups, or a $50 \%$ sucrose solution, were mixed with the milk as previously described (Fawns \& Bourne, 1953). The nature of the supplements is set out in Table $\mathbf{I}$.

Table I. Composition of daily supplement given to groups of rats (six in each); $60 \mathrm{ml} . / \mathrm{group}$ for the first 20 and $\mathbf{1} 20 \mathrm{ml}$.group for the last 5 days of the 25-day experimental period

$\begin{array}{lll}\text { Experimental groups: } & \text { I } & \text { Loganberry syrup I part, milk 4 parts } \\ & 2 & \text { Raspberry syrup I part, milk 4 parts } \\ & 3 & \text { Strawberry syrup I part, milk 4 parts } \\ \text { Control groups: } & 4 & 50 \% \text { sucrose solution I part, milk } 4 \text { parts } \\ & 5 & \text { Water I part, milk 4 parts } \\ & 6 & \text { Water only }\end{array}$

Recording of weights. This was carried out at 5-day intervals, except that, during the initial control period, one day's recording had unfortunately to be missed, leaving a ro-day interval. The figures quoted are for whole groups, the six rats being transferred to a counterpoised cage and weighed together.

Basal ration. This was weighed out and placed in 'non-spill' wire crates for feeding, one in each cage, the unconsumed portion being weighed at the end of each 5 -day period. A brand of proprietary rat cubes, claimed to be a complete diet, was used. This had previously proved satisfactory as a stock diet. The composition and analysis are set out in Table 2.

Collection of faeces. The animals were housed in metabolism cages, so that the urine drained away and was collected and the faeces fell on to a wire gauze under the 
cage from which they were collected every 5 th day. Despite the 'non-spill' feeding crates, some crumbs of unconsumed food were always found mixed with the faeces from which they were separated with the aid of a domestic potato masher. The pores of this allowed for almost complete separation of the food debris while the faecal pellets, which were larger, were retained. A few granules of food that failed to pass through the sieve were picked out afterwards with forceps. The weight of this separated food debris was added to that of the unconsumed food for each 5-day period.

Table 2. Composition and analysis of the rat cake used as basal ration

\begin{tabular}{lrlr}
\multicolumn{1}{c}{ Constituent } & $(\%)$ & \multicolumn{1}{c}{ Constituent } & $(\%)$ \\
Wheat offal & 17.7 & Meat-and-bone meal & 8.8 \\
Wheat, ground & 17.7 & Dried skim milk & 14.0 \\
Sussex-ground oats & 17.7 & Dried yeast & 1.2 \\
Maize, ground & 8.8 & Salt & 0.4 \\
Barley, ground & 8.8 & Cod-liver oil & 0.4 \\
White fish meal & 4.5 & &
\end{tabular}

\begin{tabular}{lr}
\multicolumn{1}{c}{ Analysis } & $(\%)$ \\
Total dry matter & 87.5 \\
Protein & $19 \cdot 2$ \\
Fat & 4.9 \\
Carbohydrate (by difference) & 52.6 \\
Total ash & 6.0 \\
Crude fibre & 4.8
\end{tabular}

The separated faeces were placed in brown paper bags, weighed fresh and then dried to constant weight in an electric oven at $108^{\circ}$. Drying was usually completed within $24 \mathrm{~h}$.

Preparation of the faeces for analysis. After drying to constant weight, the faeces were thoroughly mixed with a large spatula, and a representative sample was obtained by the quartering technique. This sample was finely ground in a large pestle and mortar and passed through a I mm sieve. Samples were stored in dry, stoppered bottles for analysis. A small residue of fibrous material failed to pass through the sieve and was discarded; it appeared to consist largely of coarse material- - husks and sawdust - of extraneous origin. Though some unconsumed food residue was undoubtedly mixed with this, the amount present was so small by comparison with that separated off in the initial sieving, that it could be disregarded for practical purposes.

Urine. No marked difference in the volume or appearance of the urine from the various groups could be observed. Since the difference between dietary intake of nitrogen and faecal output gives the amount absorbed, concurrent urine analyses were not undertaken. A full-scale investigation of nitrogen equilibrium was not envisaged for the purposes of this experiment.

Administration of the supplements. Preliminary trials were made with individual feeding from a pipette. This proved not only time-consuming but inaccurate, owing to loss from dribbling. In order to ensure that each animal received on an average a daily supplement of $10 \mathrm{ml}$., the water bottles were removed each morning and similar drinking bottles, containing $60 \mathrm{ml}$. of the supplements (see Table r) substituted. The 
six rats in each group competed eagerly for these, and in most instances the supplement was completely consumed in $3-4 \mathrm{~h}$, after which the water bottles were replaced for the remainder of the $24 \mathrm{~h}$ period. The double daily supplements of $120 \mathrm{ml}$./group, used in the last 5 days, were consumed within $6 \mathrm{~h}$. Small residues, occasionally left, were measured and allowed for in calculating the results. Variations in the intake of individual animals were disregarded since all recordings were made on the whole group as the unit under investigation.

Analytical methods. Nitrogen was estimated by the Kjeldahl procedure and lactose in the milk supplement by Benedict's solution as described by Plimmer (1938). The values for milk fat (Gerber method) were kindly supplied to us by the Express Dairy Co. Ltd.

Calorie value of the diet. This was calculated from the analyses, taking the values of $4^{.}$I Cal./g for protein and carbohydrate and 9.3 for fat. For the basal diet, the analysis supplied by the manufacturers, quoted in Table 2 , was taken as the basis of calculation. Protein in the milk supplement was estimated in the usual way as nitrogen $\times 6.38$, and lactose and fat as indicated. To these values were added those for the sucrose content of the syrups. The small amount of calories derived from the organic acids in the fruit juices themselves was negligible by comparison with the total intake and was omitted.

\section{RESULTS}

The weights of the groups throughout the whole experiment are set out in Table 3 .

The nitrogen assimilation is set out graphically in Fig. I. Curves for each group show the amount of nitrogen absorbed (i.e. excess of dietary intake over faecal output) for each 5 -day period.

Table 3. Weight changes $(g)$ of rats in control and experimental groups (six rats to the group)

\begin{tabular}{|c|c|c|c|c|c|c|}
\hline \multirow[b]{2}{*}{ Days } & \multicolumn{3}{|c|}{ Experimental group no. } & \multicolumn{3}{|c|}{ Control group no. } \\
\hline & $\mathbf{I}$ & 2 & 3 & 4 & 5 & 6 \\
\hline o & 862 & 837 & 789 & 850 & 867 & 835 \\
\hline 5 & 853 & 917 & 890 & 945 & 965 & 815 \\
\hline ro & - & - & - & - & - & - \\
\hline 15 & 1120 & 1082 & 1057 & 1088 & Iog6 & 1050 \\
\hline 20 & $1 \pm 62$ & 1130 & II05 & I 148 & II 42 & $113^{\circ}$ \\
\hline 5 & 1280 & 1220 & 1205 & 1275 & 1248 & 1220 \\
\hline 10 & 1328 & 1242 & 1225 & 1286 & 1285 & 1265 \\
\hline I 5 & 1360 & I310 & 1275 & I 345 & I34 I & 1322 \\
\hline 20 & I 395 & 1352 & 1306 & 1370 & 1345 & 1325 \\
\hline 25 & 1485 & 1430 & 1405 & 1.492 & 1475 & 1405 \\
\hline $\begin{array}{l}\text { Mean gain during initial } \\
\text { control period }\end{array}$ & & 304 & & & 289 & \\
\hline $\begin{array}{l}\text { Mean gain during } 20 \text { days } \\
\text { experimental period (single } \\
\text { dose) }\end{array}$ & & 219 & & & 205 & \\
\hline $\begin{array}{l}\text { Mean gain during } 5 \text { days } \\
\text { experimental period } \\
\text { (double dose) }\end{array}$ & & 89 & & & 112 & \\
\hline
\end{tabular}


Table 4 gives the total caloric intake for each group: $(a)$ for the initial control period ( 20 days); $(b)$ for the experimental period with single supplement (20 days); and $(c)$ for the final 5 days with double supplement. The corresponding gains in weight for the same time intervals are also given for each group, from which the gain in $\mathrm{g} / \mathrm{ro0}$ Cal. has been derived.

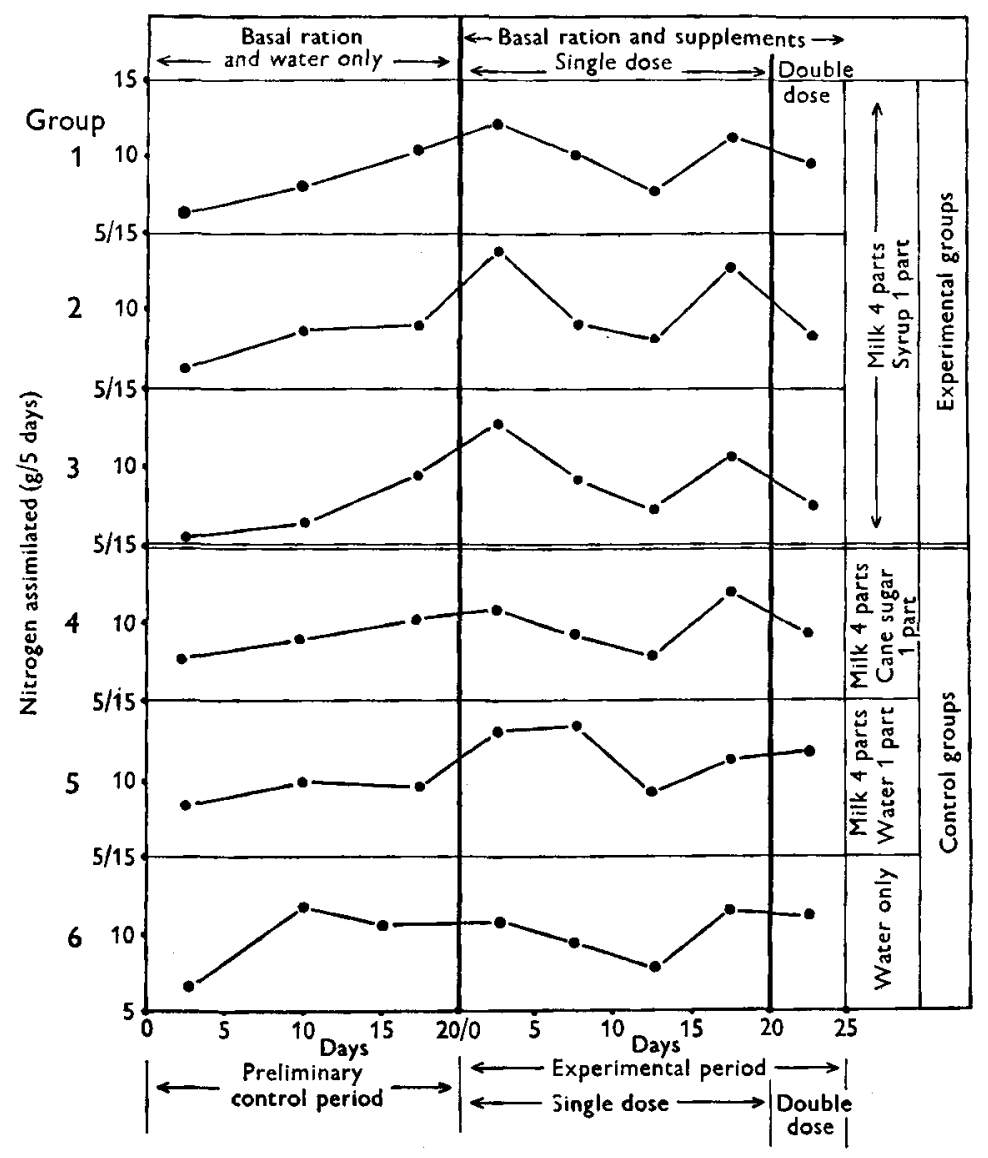

Fig. I. Nitrogen assimilation of the six groups of rats.

\section{DISCUSSION}

The 600-700 ml. pure undiluted orange juice used daily by Chaney \& Blunt (1925) in their experiment with children constituted such a large supplement that it might be looked on as a 'therapeutic measure', especially as the authors state that the two schoolgirls investigated were showing some signs of malnutrition and living on an orphanage diet. Chaney \& Blunt's experiment, therefore, falls into a different category from that on the rats outlined in this paper, where, as stated at the outset, the object was to observe the effect, if any, of fruit syrup-milk supplements superimposed on a diet already adequate.

We attempted therefore to keep the supplement down to a level comparable with 
Table 4. Relationship between gain in weight and calorie intake of groups of experimental and control rats (six to the group)

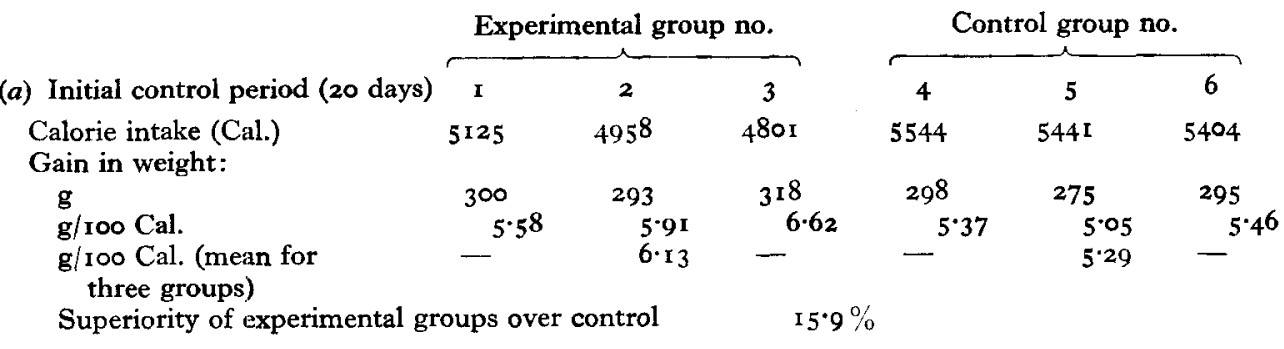

(b) Experimental period, single dose (20 days)

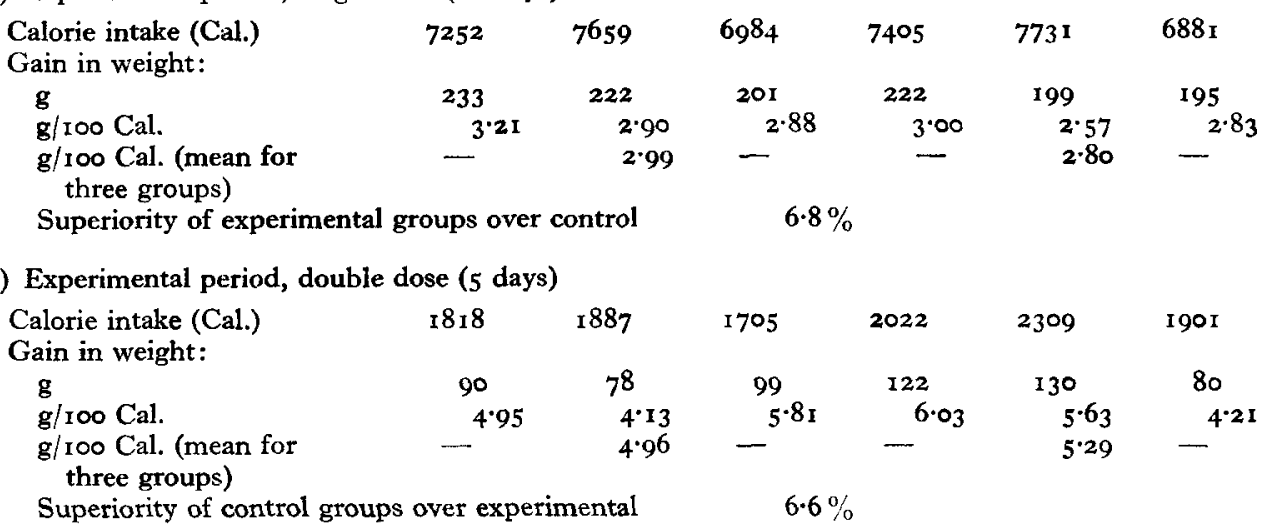

that which an adequately fed person might consume daily as an 'extra'. In so far as it is possible to compare directly two different animals species, the dosage was fixed according to the relative fluid intakes of a rat and a human being rather than on a weight-for-weight basis, as this latter makes no allowance for the greater metabolic rate of the rat. 'The daily volume of milk supplement of $10 \mathrm{ml} / \mathrm{rat}$, or $60 \mathrm{ml}$./group, was chosen with regard to the animal's total fluid intake. During the control period each group consumed approximately $200-250 \mathrm{ml}$. water daily-say $240 \mathrm{ml}$. The average human being requires 3-5 pt., say $4 \mathrm{pt}$., daily, so that the amount offered to the rats would be equivalent to about I pt. daily for a man, or two 'milk shakes', which is as much as an average person could be expected to consume regularly each day as a normal article of diet. The double supplement of $120 \mathrm{ml}$./group daily, given during the last 5 days, is equivalent to 2 pt., or four 'milk shakes', which is sufficient to affect the appetite of even the most hardened milk-bar habitué. A comparison of the calorie intakes of experimental groups $I, 2$ and 3 with controls 4,5 and 6 , in section $(c)$ of Table 4 , shows that appetite was in fact diminished, since the average calorie intake of the experimental groups was $1803 \mathrm{Cal}$. as against $2077 \mathrm{Cal}$. for the controls.

The gain in weight $(\mathrm{g} / \mathrm{r} 00 \mathrm{Cal}$. consumed), set out in Table 4 , is taken as a reflection of the assimilation of the food. During the 20 days at single dose level, the experimental 
groups show a $6.8 \%$ superiority over the control groups, which appears to be reversed after the 5 days at double dose, when the controls show a $6.6 \%$ superiority over the syrup-fed animals. This same effect is reflected in the weight gains shown in Table 3 . Here the syrup-fed groups gained on an average $219 \mathrm{~g}$ as compared with $205 \mathrm{~g}$ for the control groups, during the first experimental period, which changed to 89 and I $12 \mathrm{~g}$ respectively during the 5 days at double dose. It might be concluded that no deleterious effect was noticeable at the lower level but that at the higher the effect of the supplement was detrimental. But since larger differences between the two sets of animals had already been observed during the initial control period when both were receiving basal ration and water only, such a clear-cut conclusion would appear unwarranted.

The values for nitrogen absorption (Fig. I) show no significant change specifically referable to the syrups. In the first five groups, which were all receiving milk in their supplement, there was a rise at the commencement of the experimental period, presumably due to the milk. With the double dose, a sharp downward trend was shown by all groups receiving sucrose in their supplement (groups 1-4) and could be attributed to the increased supplement.

There was no diarrhoea or constipation. Any tendency to either condition should have been reflected in a change in the moisture content of the faeces, but values for this showed no difference between the two sets of animals throughout the experiment. The percentage values for moisture during the initial control period were as follows: experimental groups: average 24.3 (maximum 29.5, minimum 20.7), control groups, average $27 \cdot 5\left(3 I^{\circ} 7-2 \mathrm{I} \cdot 9\right)$. During the experimental period at single dose, the experimental group showed an average of $30 \cdot 4(37 \cdot 7-23 \cdot 9)$, while the corresponding average value for the controls was $3 \mathrm{I}^{\cdot} \cdot 4\left(3^{8} \cdot 7-23 \cdot 6\right)$. At double dose, the experimental group

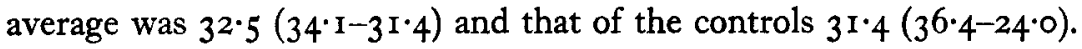

A slight tendency for the moisture content to rise during the course of the experiment was thus apparent, but this was seen equally in both sets of animals.

\section{SUMMARY}

I. Three fruit syrups, loganberry, raspberry and strawberry, mixed with milk in the ratio $\mathrm{r}: 4$ were fed to three groups of rats, and their growth rates, nitrogen absorption and calorie intakes compared with those of three control groups receiving respectively, milk and sucrose, milk and water, and water only. All groups ate ad lib. an adequate basal ration.

2. Rats receiving $10 \mathrm{ml}$. of syrup supplement daily for 20 days, showed no deterioration in general health, growth rate or calorie intake.

3. Doubling the supplement to $20 \mathrm{ml}$. daily for a short 5 -day period at the end of the experiment produced a slight diminution in the weight gains of the syrup-fed animals which, if significant, was probably due to curtailment of appetite. This was reflected by a decrease in the calorie intake.

4. No changes specifically referable to the syrups could be observed in the values for nitrogen absorption. 
5. There was no difference in the moisture content of the faeces of the two sets of animals, and no visible signs of either constipation or diarrhoea were observed.

Our thanks are due to $\mathrm{Dr} \mathrm{H}$. E. Magee for his interest and encouragement in this work, to Messrs H. W. Carter \& Co. for a gift of syrups and a grant in aid of expenses, and to the Express Dairy Co. Ltd. for a supply of standard milk of known fat content. We are also indebted to $\mathrm{Mr}$ Charles Elia for preparation of the faeces for analysis.

\section{REFERENCES}

Chaney, M. S. (1923). Amer. F. Dis. Child. 26, 337.

Chaney, M. S. \& Blunt, K. (1925). F. biol. Chem. 66, 829.

Fawns, H. T. \& Bourne, G. (1953). Brit. F. Nutr. 7, I3.

Newall, F. \& Miller, E. W. (1923). F. Home Econ. 15, 24 I.

Plimmer, R. H. A. (1938). Organic and Biochemistry, 6th ed., p. 530. London: Longmans, Green and Co. 